\title{
Investigation on Tabriz University Teachers' Experiences of the Ignored Curriculumin General Courses
}

\author{
Yousef Rezapour ${ }^{1}$, Sajjad Purbaghban ${ }^{2 *}$ \\ ${ }^{1}$ Educational Sciences Group, University of Tabriz, Tabriz, Iran \\ ${ }^{2}$ University of Tabriz, Tabriz, Iran \\ Email: sajjadpoorbaghban@yahoo.com
}

Received 11 April 2014; revised 16 May 2014; accepted 24 May 2014

Copyright (C) 2014 by authors and Scientific Research Publishing Inc. This work is licensed under the Creative Commons Attribution International License (CC BY). http://creativecommons.org/licenses/by/4.0/

(c) (i) Open Access

\section{Abstract}

The ignored curriculum is one of important elements in the curriculum that the design of this concept has led to reduce a superficial look at measures to curriculum. Ignored curriculum not only in the design but also should be considered at the implementation level. The present study examined the experiences of teachers in general education from ignored curriculum in higher education and this study was done by qualitative research and its approach was interpretive phenomenology. In this regard, semi-structured interviews were conducted with twenty-six teachers of general education courses and the data obtained from these interviews were analyzed by using phenomenology of Smith. Three major themes from ignored curriculum, were found from the experience of teachers including 1) lack of attention to requirements which consists of three sub-categories: in attention to the needs of the learner, the needs and demands of everyday life and the needs of experts; 2) lack of attention to content; 3) run into problems involving the four sub-problems of teaching, evaluation time, space and assessment. The teachers during the training and implementing courses have gained a lot of experience from the ignored curriculum that had impact on their perception. Planners are familiar with academics experiences and identify ignored curriculum of general education courses and emphasized on how they understand the main goals of general education courses and made it meaningful and they had a main role in eliminating the flaws of this course, and enhance the effectiveness of them. In summary, the results obtained from the study were that general education courses, do not address the needs of learners. These requirements include of three sub-categories: inattention to the needs of the learner, routine needs and professionals. Also, courses have less attention to content. And there are problems such as difficulties in teaching this lesson, time, space and evaluation.

\footnotetext{
*Corresponding author.
} 


\section{Keywords}

\section{General Education Courses, Ignored Curriculum, Higher Education, Students}

\section{Introduction}

The curriculum includes general education components which are not belong to a particular field of knowledge. Although the dimensions formed of the various areas of human knowledge, the term "public education" shows that it is only for particular field of science and it is considered for all learners and students.

In definition, it can be say that curriculum programs in public higher education as a formal part of the under graduate courses that presented to all students alongside the main course [1]. General courses are included foreign language, physical education and family planning, Persian literature and Islamic studies.

Religion course is as a general education course belonging to all disciplines in the universities of Iran and presented in 5 trends in theoretical foundations of Islam, Islamic ethics, Islamic history and Islamic civilization and familiar with Islamic sources; and 12 units of the 32 units will be optional; and students should be able to choose from 12 units of general education 32 units offered courses [2].

Curriculum, teaching and learning activities make it possible to achieve learning goals. The curriculum includes a variety of formal curriculum, hidden, and ignored. Among those who have attempted to introduce a variety of curricula, it can be mention Eisner [3] that is divided into the Explcit, program Emplcitor Null.

Eisner in his debate argued that those things that students learn by explicit curriculum are much smaller than they learn by implicit or hidden curriculum. He also noted that there are things that the school curriculum refuse to teach them.

Accordingly, Eisner believe that the basis for ignored curriculum included the knowledge and values that schools do not attempt to teach them. Although it may be more valuable than the things that are taught by the school [4].

One of the most frequently discussed and controversial aspects which have long formed the heart of problems in curriculum is that what things should be taught in schools? Which subject or content is valuable?

What criteria should be used in selecting topics for inclusion in the curriculum, and finally, who should be involved in this process?

All of these questions revolve around a fundamental issue and it is the needs assessment and its use in the curriculum [5]. This needs assessment process cause to preparation of programs that provide students with the educational system for teaching and learning in the curricula of formal (explicit) curriculum.

In this regard, it is important to remove the attention of practitioners and decision makers curriculum to reflect and think about what the agenda of the education system and formal explicit curriculum. Null curriculum, blacked out, unproductive and neglected are translations that used as synonym against null curriculum. Curriculum thinkers have been mentioned to a variety of curricula.

Although often different titles have been used by the same meaning but we cannot deny successful efforts to identify and introduce the types of curriculum specialists in this field [6]. Ignored curriculum by Eisner includes in terms of knowledge and values that' schools do not attempt to train them though their value and maybe they have higher value than things taught in the school.

In Eisner analysis of activities in the school in introducing ignored curriculum, the subject has attracted the attention of other scholars [7]. Also Goodlad [8] discussed the concept and "Nadingez" and "Sorton" in 1986 have focused on this topic. Unspoken or unnoticed curriculum itself is divided into two categories: implicit and explicit.

It is intended to be diagnosed and treated by the examination syllabus, because as we confront illnesses in healthy people, the signs are hidden, as in the case of cancer, especially in view of the surface, has no signs or symptoms.

Strategy exploration in depth review of curriculum areas is planned and implemented. Additional important point that needs to be considered carefully is that how this topic is updated and suits to time that inform us from impotence of curriculum. Explicit unspoken or ignored curriculum perhaps can be introduced by deleted program. In this aspect of program, some items arises which has been avoided due to the arrival of the curriculum. 
In fact, what kind of things that should be present in the curriculum, but due to ignorance and negligence of has been deleted in education [9]. The unspoken or ignored curriculum basically doesn't happen and is deleted and the lack of it is clear in official curriculum. This topic can be set aside, consciously or without knowing the agenda. So unspoken or ignored means what is not exist, but really should (or could) be.

This concept has a negative and deprivation impact. Therefore, the discussion of the curriculum is a very serious matter. Therefore, the education system needs to go away from tradition and habit, and due to the fluidity and dynamic curriculum, according to the requirements when—where-social—political—economic and shall monitor the curriculum.

The main message of this curriculum (ignored) is that the dialogue between what is and is not continue and involved in systematic curriculum to compel critical thinking and refresh in this category [8].

\section{Literature}

In this regard, there aren't direct researches, so it would be mention to indirect researches in this field: Safarnavade [10] conducted the research in the social studies curriculum in guide school and pointed to the ignored curriculum as distinct the planned curriculum from ideal curriculum that didn't enter to planned curriculum deliberately or undeliberately.

He compared that's what the social studies curriculum and what is expected and provide evidences that there are differences between the two. This difference is introduced as ignored curriculum. He also compares the social studies program in students with an interest in the concepts of harmony, life skills and familiarity with the institutions of rural life among the issues raised in the public education curriculum as ignored topics in social studies curriculum.

Levine [11] expressed in the study entitled "The gaps in the curriculum of business education": there is not coordination among those planning, implementation and experience and teachers, industrial people and academic members have different attitudes about neglected areas of learning in the curriculum in Iran and put entrepreneurship as his axis and notes that our educational system must take an entrepreneurial approach that tonon-entrepreneurial educational system dot give opportunity to reveal the talent and creativity of children and concludes that national attitudes to entrepreneurship as essential for the determination of the international system, and then analysis Iran's high school writing curriculum Human sciences based on two common ways it means explicit and implicit ways to describe the objective and the method of inference and presents an index about ignored components Safarnavade [12] conducted the research in the social studies curriculum in guide school and pointed to the ignored curriculum as distinct the planned curriculum from ideal curriculum that didn't enter to planned curriculum deliberately or undeliberately. He compared that's what the social studies curriculum and what is expected and provide evidences that there are differences between the two. This difference is introduced as ignored curriculum. He also compares the social studies program in students with an interest in the concepts of harmony, life skills and familiarity with the institutions of rural life among the issues raised in the public education curriculum as ignored topics in social studies curriculum.

A study by Arefi [1] entitled "Necessity of improvement in General Courses of Course Curriculum in Master of the students' view of Sciences, Humanities and the Faculty of Engineering and academic members of Beheshti University" was performed. Based on the identified results, the general education curriculum from the perspective of students and faculty is essential to reduce the number of courses in Islamic Studies and Review the content and titles of courses and optional courses chosen from the university were the higher priority in students.

The perceived about the lack of Islamic Studies courses success in achieving its objectives and implementation of these lessons and also provide special importance of these lessons in life and students' work and not explained properly functioning can the reasons for the high volume of student requests to reduce the number of units of theology courses. In this study, there aren't significant differences between students in different courses like basic sciences, humanities, and engineering. One study have been done by Majidi and Fatehi [13] entitled "Students' attitudes toward organized religion course at Tehran University program" and has reached the following conclusions:

1) Religion Course content to be written in a form that these lessons can have role in students' leader thought. 2) Just over a third of the students have positive attitudes in three variables of updating religion course content than beliefs questions and political, deepening religious belief, regarding positive religious values and streng- 
thening positive behavior and others have no idea or are disagree. 3) Islamic course content in terms of strengthening the intellectual and practical skills. Religious and also, providing knowledge needs of students are not suitable. 4) Islamic course content in terms of having psychological literature, appealing and believable are not in a favorable condition.

\section{Methods}

This is a phenomenological study which used the experiences of Tabriz University professors in general courses of the ignored curriculum. Sampling was theoretical that in theoretical or purposive sampling, the researcher usually tries to be targeted, based on what kind of specific information, the following preliminary findings is required, examples selected.

Then later on who should be elected, have already been affected by who came before and what information is given [14]. The interviews allow the researcher to ask the deeper questions, to give participants the opportunity to describe their experience with a narrative or story [15].

In this study the concept of ignored curriculum described to participants and a general and initial question exist to startan interview and asked each respondent group that what factors (content) should be given for program planners in developing books but has been neglected, Therefore, more interviews, depending on the response of each professor continued. Examples of questions and emerged in the study were as follows: How familiar are you with the concept of null curriculum? Which are neglected factor in the courses you teach (the purpose, content, learning activities and, ...)? In your opinion was ignored because some elements of what courses? Which factors are neglected in courses run? What is your problem in this course? If you are the author of this lesson, you've got to consider what the content is not included in this lesson?

Then the participants were asked to rate 30 to 45 minutes of interview time and place to make your own determination. Interviews continued until data access in-depth, interviews were transcribed and analyzed using words or phrases that seemed to be related to ignored curriculum were selected. Separating content into sentences, making convert and reshape sentences was conducted separately for each interview. Further work was carried out to confirm the validity and reliability of data, in this case to ensure the credibility perceptions of teachers talking, summarizing their own, were presented and they announced their opinions about coordination with researchers' idea and if there were any conflicting, perceptions of the researcher was amended.

Tomoral considerations before starting the interview, participants were informed of the purpose and importance of the study and participated in the study by informed consent and they were assured that the information obtained will be used solely for research purposes, and not be given to persons other than the researcher.

The purpose of the research:

Identifying the teachers' experiences in ignored curriculum in general education courses at University of Tabriz.

Research questions:

1) Which factors are ignored in public education?

2) Which factors are ignored in the implementation of general education courses?

3) What are teachers' experiences of ignored curriculum?

\section{Findings}

Based on the interviews that were conducted in order to answer the research questions the following categories were obtained, which include teachers' experiences of the curriculum in general education courses in academic units. The concept implies that teachers have the particular experiences of general education courses in university. Then, as shown by the experiences of teachers of general education courses were the overall experience. Here factors mentioned that obtained from ignored curriculum: A scan be seen, the teachers' experiences of the curriculum was divided into three main themes, which obtained results has been expressed. 1) Lack of attention to requirements, which consists of three sub-categories: inattention to the needs of the learner, routine needs and professionals: participants stated that in this course less attention has been given to widespread interest and student is idle due to lack of time in the classes and at the end of each chapter, practical activity put regarding learners' interests and students can have activity in fields of their interest and also, there is no attention to the daily needs of students and issues such as benefit of prayer, gossip, slander, and other current issues that students face with them and there are social issues that students are dealing with it and students of religion (Shia 
and Sunni) have certain beliefs that should be considered in the compilation of the book.

This course is considered to be in everyday issues and concerns and there's more to be dealt with difficulties encountered by students morally.

In compiling this book, particularly the interpretation of the Koran that is leading people to live, there would be attention to learners' needs.

The participants expressed that they will try to compile a book of prominent experts and use scholars ones and it is better used qualified teachers' experiences in compilation of the book.

In compiling this book, it should be used better qualified teachers and a group of professional writers just for a special religion book and should be considered the nature and needs of them.

2) Lack of attention to the content: About the content, the majority of participants expressed that there would be attention to the book's content during compilation that is sometimes overlooked. Participants expressed that the content is repetitive and uniform and there should be trying to remove duplicate content and book are drawn regarding the objectives of the courses because occasionally observed that some lessons become away from their original goals, and try to make content attractive for students and consider to functional aspect of religious book and content of education courses should be designed to be applicable to practical living and get out of non-attractive form.

"A lot of materials that is taught in college, have been studied in high school, so duplicate content should be removed and also many materials are not update and these shortcomings must be addressed."

In the course of the revolution, there is not any attention to revolution content and less attention has been given to external factors and policy and more attention are on the event date, so there should be enough attention to other character and ethnicities who have contributed to revolutionizing.

3) Problems of implementing involved the four sub-categories of teaching, time, space and the evaluation: in the implementation of general education courses, the participants stated that sometimes general education courses overlooked by university professors or due to lack of time, the professors do not have sufficient time to answer questions from students and participants expressed that they would try to run the half of the question and answer session and doubts that are in the minds of learners and teaching should be out of teachers' active in the class.

On the role of teachers, the participants expressed that much attention should be on teachers and their selection and try to select teachers who are professional. Because the teachers are as a paradigm in general education courses and also students affected by them.

In relation to time, the time must be increase. So professors can respond to the question of learner. General education courses are taught mostly in unsuitable time and also try to consider to regulation of presenting some courses for example Thoughts $1 \& 2$ presented in one year distance because of relationship among discussions rather than student pass Thought 1 in Semester 1 and Thought 2 in his sixth semester.

Also the participants stated that the other important factor that did not notice at all, is the large number of students in the class that this large number remove possible questions and answers among the learners, and it is boring for the most students. We are trying to teach the proper tools and training and try to teach general courses at the appropriate time that is neglected.

"Most of these courses must be paid to the question and answer sessions and feedback from students and professors should try to enforce the students' belief and guide them so that they do not forget the main aim of general courses.”

Participants stated that another factor which neglected in general education and it is important is that students in this course are only think to pass and the purpose of students in these courses is gain a score and this matter should be considered and change creates in evaluation method.

"Students with any culture, religion or belief, pass public courses just for gaining score and they do not pay attention to its functional content."

\section{Discussion}

The aim of this study was to investigate teachers' perceptions toward ignored curriculum and it was conducted by the phenomenological approach and by using qualitative research. The results indicated that from the perspective of the participants in this study, general course is one of the most important lessons that should have more attention to learners' interest and makes student satisfaction and also students expressed that a group of 
professional experts regarded to develop books for general education courses in order to identify students' needs and also identify such everyday issues that surround learners and get help from the professors who teach these courses. According to Shugrunsky [11], it can be said that to avoid ignored curriculum, there should be examined all aspects of the curriculum.

Fathi \& Momeni [6] stated that the issue regarding the motivations, interests, needs, attitudes and experiences of students is a major factor in curriculum planning and this factor that facilitate the teaching process-learning is regarded as the basic function of the system of higher education. Safarnevadeh [10] said that one way to consistently compare ignored curriculum with social, cultural, economic, political is when we find that their compatibility.

This finding is in line with Aghajani [16] who states the general curriculum should be appropriate with the political, social, moral society that young people need in today's world and can be avoided to discuss about implicit problems and also in a line with findings of Majidi and Fatehi [13] who concluded that Islamic courses must be written in a form that can be guidance for leaders and students.

The participants expressed that content is non-attractive and repetitive, so professionals in general courses must try to delete them and pay attention to religious courses’ purpose.

According to Safarnevadeh [10], the first point to note in ignored curriculum is that we must be cautious about the selection of curriculum content and replace them. The second issue is that in considering ignored curriculum that encourages us to examine educational goals and select objectives that can be identified in content.

Know one of the most important issues in the course of planning curriculum is pay attention to modernize and revise in lesson plan and coordinate the content and methods of teaching with changing and uncertain conditions. This finding is consistent with Majidi and Fatehi [13] finding who express that:

1) Slightly more than one-third of the teachers have positive ideas about three variables of updating ingeneral course content than their beliefs and political questions. Deepening religious beliefs and training positive values of religious, spiritual dimensions and strengthening positive behavior and others don't have any idea or are disagree

2) Content of basic course in terms of strengthening the intellectual and practical skills for students are not suitable.

3) Basic course content in terms of having fluency literature and appealing is not in a favorable condition. The findings revealed that general education courses in terms of implementing faced with some problems such as teaching, time, space and evaluations. From the participants' perspective, teaching methods should not be just speaking by teacher because of the high volume of books and lack of time, so the amount of content will be reduce for holding a question and answer session.

And students can ask their questions, and also be careful in selecting teachers for general courses who don't have certain biases and pay attention to the needs of learners by patience and clear doubts from their minds because teacher acts as a model in the class. But sometimes due to the lack of time and large content of books, teacher cannot do his duty. Teachers' behavior and teaching are the most important factors in hidden curriculum that will affect on the attitude of students.

Courses should be taught in terms of time, for example 12 to 2 or 2 to 4 hours are not right time to deliver these lessons. And it is better have more attention to the general course. About the classrooms pace, participants stated that there is no training for courses such as projector and there are large number of students in general education classes which one of the factors that are not taken into consideration.

Parsa \& Saati [17] stated about teaching and teachers' role, so teaching is one way to facilitate learning and teachers are eager to develop students' skills in thinking. But by tendency to speech and emphasize on concepts cause decline in learning standard levels. Academic members have major responsibility toward student learning and should undertake lifelong learning in themselves. But because teachers tend to focus on the ways of knowledge transfer within a certain range of domain to the minds of students, increased students' desire and attachment to teachers, lead to more serious difficulties to their learning.

These findings are consistent with the results of the Izadi [2] who has stated that the following results: 1) There would be little attention to general education courses that offered by some authorities and lack of their presentation in appropriate hours for learners and in the poor environment; 2) Pay less tuition to teachers of general education courses than other courses which cause teachers have less attention to this course; 3) Presenting general course with a very high number of students, although students are required to exploit favorable conditions. Also, they are in line with Aghajani [16] results which are as follows: 1) Professor should exploit bila- 
teral, question and answer techniques instead of presenting courses as unilateral. 2) Professor, in addition to the scientific relationship must have the emotional relationship with students so that general courses not only put in the minds of students, but also affect their lives. 3) Professors expand their knowledge in the field of general education courses. 4) Reduce the number of students in the class in order to enhance the quality of education. 5) In order to study, in addition to teaching, there should be more attention to research. Also findings are consistent with the results of Ahmadi [18] who concluded that although science curriculum has appropriate design, it faces with many problems in implementation stage. They have a negative attitude toward all factors, such as course textbooks, teaching methods, school climate prevailing regulations, the impact of religious organization, practical aspect of theology. In this regard, Nasseri [19] expressed some factors such as lack of access to educational materials, pushing toward teaching, incorrect assessment and evaluation practices as important causes of failure in achieving the objectives and defined standards in the curriculum[20]. Mahram and colleagues [21] also argue that the design of questions is based on goals related to areas of lower cognitive questions, multiple choice questions, the lack of completion of the evaluation step and density implementation which resulting anti-training in higher education. The results are in line with Ashrafzadeh [22] findings that the lack of appropriate evaluation criteria in general courses is aligned with Mahrametal findings. To explain the findings of the research, it can be say that some factors such as: ignored curriculum in duplicate content, lack of attention to the overall needs of the community, lack of content, lack of proper relationships between students and teacher to receive personal affairs and passive teaching methods, lack of knowledge in teachers, focusing exclusively on the use of lecture and maintaining relationships with other students in the class, high number of students in the classroom and lack of time time and less number of education courses and false assessing practices affected on students' belief and attitudes towards this lesson.

\section{References}

[1] Arefi, M. (2007) The Need to Improve the Work Master. The rate of curriculum of Courses in Students' View of Sciences, Humanities and the Faculty of Engineering and Martyr Beheshti University, Journal No. 10, Studies Curriculum.

[2] Eizadi, H. (2003) Determining the Position of Religion Course in College, the Supreme Council of Cultural Revolution Newsletter.

[3] Eisner, E.W. (1994) The Educational Imagination: On the Design and Evaluation of School Programs. Macmillan, New York.

[4] Eisner, E.W. (1994) Cognition and Curriculum Reconsidered. 2nd Edition, Teachers College Press, New York.

[5] Fathi Vajargah, K. and Momenimahmooee, H. (2001) Basic Principles of Curriculum, Tehran, Iran.

[6] Fathi Vajargah, K. and Momenimahmooee, H. (2005) Study of Factors Affecting Participation of Faculty Members in Academic Curricula. 131-154.

[7] Shugrunsky, D. (2004) Type of Curriculum in Citizenship Education. www.epea.asu.edu/epaa/u7n29.htm1

[8] Goodlad, J.I. (1984) A Place Called School: Prospects for the Future. McGraw-Hill, New York.

[9] Wilson, L.O. (2005) What Are the Types of Curriculum. www.uwsp.edu/education/Lwilson/currhc/curtyp.htm

[10] Norrozzade, R. (2005) Hidden Curriculum in Higher Education, No. 33.

[11] Levine, R. (2008) Finance and Growth: Theory and Evidence. In: Aghion, P. and Durlauf, S., Eds., Handbook of Economic Growth, North-Holland Elsevier Publishers, Amsterdam.

[12] Safarnavadeh, M. and Moosapour, N. (2007) Neglected Social Studies Curriculum-Summary of the Seventh Congress of the Iranian Curriculum Studies Association. Middle and Secondary School Curriculum. Challenges and Prospects, Tehran, Tarbiat Moallem University.

[13] Majidi, M. and Fatehi, A.(2004) Students’ Attitudes toward Religion course planning program. www.sid.ir

[14] Haj Bagheri, M. and Akbari, H. (2006) Severity of Disability and Its Related Factors in Elderly. 33, 225-234.

[15] Porter, S. (1996) In: Cormack, D.F.S., Ed., The Research Process in Nursing, 3rd Edition, Blackwell Science, Edinburg.

[16] Aghajanighanad, M. and Farzandvahi, J. (2000) Investigation on Islamic University Students' Attitudes towards Islamic Studies, Research, Education and Elam Center.

[17] Parsa, A. and Saketi, P. (2006) Learning Approaches, Learning Outcomes and Student Perceptions of the Implemented Curriculum. Humanities and Social Sciences, Shiraz University, Number 3.

[18] Ahmadi, R.H. and Matsuo, H. (2000) A Mini-Line Approach for Pull Production. European Journal of Operational 
Research, 125, 340-358. http://dx.doi.org/10.1016/S0377-2217(99)00390-2

[19] Nasseri, D. (2007) Identify Neglected and Unnecessary Primary School Curriculum Based on the Views of Teachers. Master's Thesis, University of Tabriz, Tabriz.

[20] Mahmuee, H. and Zare'ian, Gh. (2010) What Is Curriculum Evaluation Function? http://sitwe.wordpress.com/2010/10/29/the-role-of-formative-,summative-andsummative

[21] Mahram, B., Saketi, P., Masoudi, A. and Mehrmohammadi, M. (2005) Component of the Identity of the Hidden Curriculum Education. Journal of Curriculum Studies.

[22] Ashrafzadeh, F. and Faraji, M. (2005) An Epidemiological Study of CP in Rehabilitation Centers in Mashad. Hormozgan Medical Journal, 9, 235-239. 